\section{Lymphoepithelioma like Skin Cancer: an Exceedingly Rare Primary Skin Cancer}

We would like to share our case of lymphoepithelioma like carcinoma of the skin (LELCS) and further expand on this extremely rare primary skin cancer. In August 2013 a 79-year old man presented with a short history of an asymptomatic $9 \mathrm{~mm}$ pearlescent nodule on the left medial cheek. There was no history of trauma or an insect bite and clinically it resembled a basal cell carcinoma so no photographs were taken. A diagnostic superficial shave biopsy revealed a dermal nodule composed of islands of epithelial cells which show quite marked atypia and scattered mitoses (Figure 1a). Immunohistochemistry staining showed positive staining of the epithelial cells for cytokeratins and EMA and the overall appearances were suggestive of LELSC and so a wide local excision of $10 \mathrm{~mm}$ was arranged. Further histological examination revealed a completely excised tumour composed of aggregates of malignant undifferentiated cells surrounded by a dense reactive lymphoplasma cellular infiltrate (Figure 1b). Immunohistochemical analysis showed up positive for cytokeratins (KL1 and EMA) as regards to epithelial cells. The lymphocytic infiltrate was positive for LCA, CD3

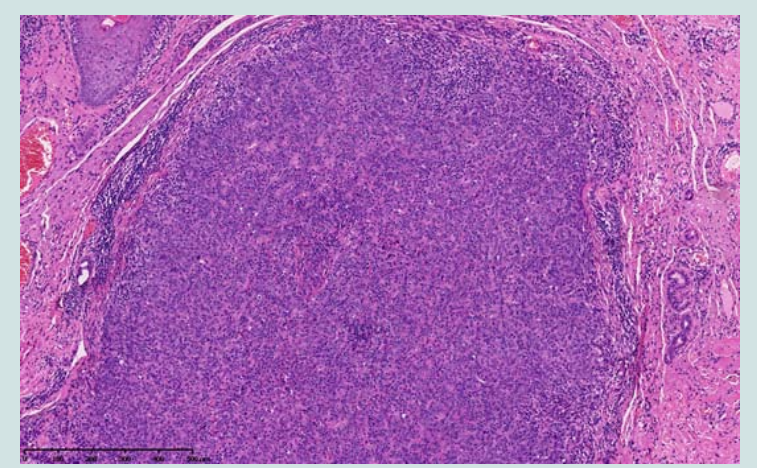

Figure 1a: Dermal nodule with atypical epithelial cells and lymphocytes (Haematoxylin and eosin, original magnification $\times 200$ )

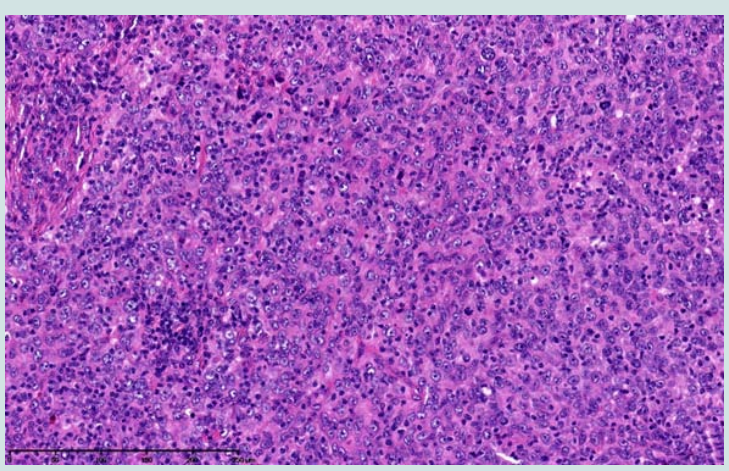

Figure 1b: Atypical epithelial cells with scattered mitoses (Haematoxylin and eosin, original magnification $\times 300$ )

\section{Journal of}

\section{Clinical \& Investigative} Dermatology

\author{
Arif Aslam $^{1 *}$, Anand Patel $^{1}$, Kusum Kulkarni ${ }^{2}$ and \\ Sandeep Varma ${ }^{1}$ \\ ${ }^{1}$ Department of Dermatology, Nottingham NHS Treatment Centre, \\ Lister Road, NG7 2FT, Nottingham \\ ${ }^{2}$ Department of Histopathology, Queen's Medical Centre, Derby Road, \\ NG7 2FT, Nottingham

\section{*Address for Correspondence} \\ Arif Aslam, Post-CCT fellow in Mohs surgery, Nottingham NHS \\ Treatment Centre, Queens Medical Centre Campus, Lister Road, NG7 \\ 2FT, Nottingham, Tel: 07595 913107; E-mail: a.aslam@doctors.org.uk

\section{Submission: 12 October 2015} \\ Accepted: 14 December 2015 \\ Published: 18 December 2015 \\ Copyright: (c) 2015 Aslam A, et al. This is an open access article \\ distributed under the Creative Commons Attribution License, which \\ permits unrestricted use, distribution, and reproduction in any medium, \\ provided the original work is properly cited.
}

and EBER (Epstein Barr virus encoded small RNA) negative with EBV antibody (Figure 2). Electron microscopy analysis revealed rounded and occasionally spindle-shaped poorly differentiated squamous epithelial cells, and a lymphoid stroma consisting mostly of normal appearing small lymphocytes. Collectively, these appearances were in keeping with a rare entity known as LELCS and re-excision of the area was arranged with no evidence of residual LELCS in the sections examined.

Our patient underwent three month follow up for skin surveillance and lymph node examination and in October 2014 a left sided neck lymph node was detected on clinical examination. Subsequent ultrasound guided fine needle aspiration revealed malignant cells consistent with metastatic LELCS and he underwent a left sided modified radical neck dissection and superficial parotidectomy with 4/42 nodes positive for disease. Flexible nasoendoscopy showed no abnormality and adjuvant radiotherapy is underway.

Primary LELCS is an exceptionally rare cutaneous malignancy of uncertain origin and was first described by Swanson et al. in 1988 as a primary neoplasm with microscopic similarity to undifferentiated carcinoma of the lymphoepithelioma [1]. It usually presents as a skin colored solitary nodule or firm plaque with a predilection for the head and neck affecting both men and women equally between the ages of 39-96; there are less than one hundred cases reported in the literature so far [2].

It is histologically distinct from other primary skin tumours showing well defined lobules or nests of large epithelioid cells densely associated with a mixed $\mathrm{T}$ and $\mathrm{B}$ cell lymphocytic infiltrate. The epitheliod component has no connection with the epidermis and the cells have poorly defined eosinophilic cytoplasm with prominent nuclei and atypical mitotic figures. The main differential diagnoses include undifferentiated nasopharyngeal carcinoma or metastatic lymphoepithelioma from other sites, cutaneous lymphoma or an adnexal tumour. 


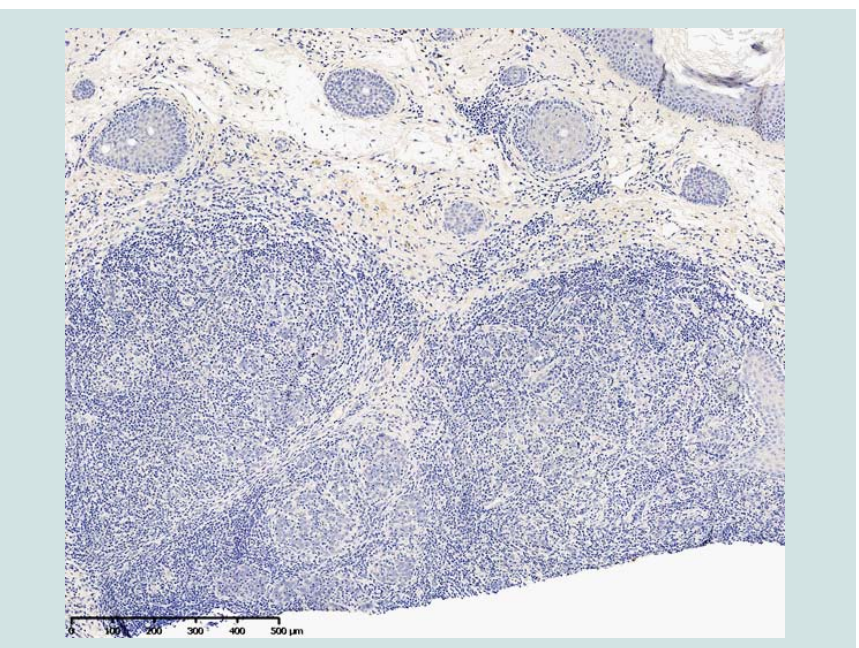

Figure 2: Immunohistochemical staining for Epstein Barr virus encoded small RNA was negative (original maginification $\times 100$ ).

Treatment includes complete surgical excision with radiotherapy used in patients with incomplete surgical margins. LELCS has a relatively good prognosis with low metastatic potential and among all reported cases, $78 \%$ patients were free of disease after treatment and $10 \%$ had local recurrence. Two patients developed lymph node metastases with a fatal outcome [2].

There is an uncertainty regarding the aetiology and histogenesis of LELCS and a thorough clinical work up with imaging, ENT examination, and immunohistochemistry are recommended for the diagnosis and treatment. It is thought that EBV is responsible in most extra-cutaneous sites; however EBV has not been reported in the primary skin type except in one case [3].

\section{References}

1. Swanson SA, Cooper PH, Mills SE, Wick MR (1988) Lymphoepithelioma-like carcinoma of the skin. Mod Pathol 1: 359-365.

2. Welch PQ, Williams SB, Foss RD, Tomaszewski MM, Gupta A, et al. (2011) Lymphoepithelioma-like carcinoma of head and neck skin: a systematic analysis of 11 cases and review of literature. Oral Surg Oral Med Oral Pathol Oral Radiol Endod 11: 78-86.

3. Aoki R, Mitsui H, Harada K, Kawamura T, Shibagaki N, et al. (2010) A case of lymphoepithelioma-like carcinoma of the skin associated with Epstein-Barr virus infection. J Am Acad Dermatol 62: 681-684. 